\section{LABORATORY ANIMALS BUREAU}

HE Laboratory Animals Bureau, a unit of the Medical Research Council housed at the Council's laboratories at Holly Hill, Hampstead, London, N.W.3, has published Vol. 1 of its "Collected Papers"*. As Dr. H. J. Parish explains in his foreword to the volume, the Bureau was established in 1947, and its first director was Prof. R. E. Glover, who is now professor of veterinary pathology in the University of Liverpool. After a vigorous start on its useful career under Prof. Glover's experienced guidance, the Bureau is now directed by Dr. W. Lane-Petter, and most research workers who use experimental animals know the work of the Bureau so well that its value needs no emphasis. There will, nevertheless, be many who will welcome the informa. tion contained in this volume.

In the first article, Dr. W. Lane-Petter discusses the problems with which the Bureau has to deal, the uses to which experimental animals may be put, the sources of their supply, the problems of procuring them and of maintaining adequate supplies of them, and certain special problems, such as the provision of uniform strains and animals free from infections.

When, however, these problems have been overcome, the further problem remains of managing and properly feeding the animals in the laboratory, and Prof. A. N. Worden deals with this subject of diets and management in an article based on his experience and special study of the subject. Mr. A. E. Mundy, secretary of the Laboratory Technicians Association, which was founded in 1950 to improve the training and status of the assistants who do the important work of looking after laboratory animals, discusses the functions of these assistants, who are, as every research worker will agree, essential factors in all schemes of research which must employ experimental animals. Mr. J. Scarnell discusses the equally important subject of the control of infections of laboratory animals with diseases which may suddenly wreck experimental work. In an article on the provision of animals for research, Dr. J. S. Paterson, of Porton, gives, from his wide experience of both research and the provision of animals for others, a valuable account of the various problems that arise. $\mathrm{He}$ discusses the functions of breeders and dealers and the accreditation scheme for commercial breeders that is supervised by the Laboratory Animals Bureau. The Bureau proposes to issue "Collected Papers" each year, and material for inclusion in it may be submitted to the director.

The Bureau has also issued a "Catalogue of Uniform Strains of Laboratory Animals maintained in Great Britain" $\dagger$. The Catalogue contains details of the origin, pedigree, description and methods of management of laboratory animals maintained in Britain which are "thought to show a reasonable degree of uniformity". It is not claimed that this is a complete list for the whole country, but it is hoped that laboratories that have not yet sent in contributions to the Catalogue will do so in the future. Strains kept by commercial breeders will also be included if they qualify for inclusion. As the Catalogue says: "A useful degree of uniformity is an essential criterion. Hence many of the strains

\footnotetext{
* Laboratory Animals Bureau. Collected Papers, 1953. Vol. 1. Pp. $66.5 s$.

+ Catalogue of Uniform Strains of Laboratory Animals maintained in Great Britain. Pp. iii $+70,2 s, 6 \vec{d}$

(Laboratory Animals Bureau, M.R.C. Laboratories, Holly Hill, London, N.W. 3 ; 1953.)
}

listed are not strictly inbred, but are random mated in closed population and found by those maintaining them to be sufficiently uniform for their purposes. Whether or not strict sib-mating would increase the degree of uniformity to such a degree as to justify the additional trouble involved is an open question. The answer probably lies in the use to which the animals are to be put. But there can be no doubt that the conditions of management are profoundly important and it is for this reason that much space in the Catalogue is taken up by providing such details."

A feature of these two publications is the picture they give of the humane spirit in action, not only on behalf of the animals with which the Bureau is concerned, but also against disease and the suffering it causes to man and other animals. They also show the valuable results that come when medical men and veterinarians work together in what is, after all, a common field of beneficent activity.

G. LAPAGE

\section{POPULATION OF LONDON, 195I}

THE first of the "County Report" series of tables based on the 1951 Census covers the Administrative County of London*. The tables relate mainly to the numbers, distribution according to age, sex and marital condition of the population of the county, and to the structure of the private households and the conditions in which they were housed. In addition, there are tables relating to birthplace and nationality and to the "Social Class" distribution of the male population. Separate figures are given for the City of London and the twenty-eight metropolitan boroughs. Statistics relating to occupations, fertility and other matters on which information was obtained at the Census are not included in the County volumes but will be published in a series of special reports.

The present volume is of general interest as providing a summary account of some of the social changes which have occurred in London during the past twenty years. Many of these changes were either directly due to the Second World War or greatly accelerated by it. The continuous decline in the population of the Administrative County which began between the 1901 and 1911 Censuses has continued. The total population enumerated in the 1951 Census was $3,347,982$ as compared with $4,397,003$ at the 1931 Census. The estimated resident population of Greater London, however, increased slightly between these Censuses, the proportion in the outer ring having increased from 47 to 60 per cent of the total. The decline in the population of the inner area has been unevenly spread over the various metropolitan boroughs; the weighted average per cent decline was 23.9 per cent, but Poplar, Shoreditch and Stepney lost more than 50 per cent of their 1931 populations, whereas Hampstead, Lewisham and Woolwich gained $7,3.5$ and 0.7 per cent, respectively.

The reduction of the total population and its unequal incidence in different parts of the County, and the unequal incidence of enemy bombing and post-war building have combined to modify the pattern of housing conditions which existed in 1931 . Crude averages representing percentages of total population living at given numbers per room may be misleading indicators of the extent of overcrowding.

* General Register Office. Census 1951, England and Wales. County Report, London. Pp. $1+90$. (London: H.M.S.O., 1953.) 228. 6d. net. 
Nevertheless, it is interesting to see that the percentage of all persons living at more than two per room in the whole County was 2.55 per cent in 1951 against $13 \cdot 13$ per cent in 1931. Some remarkable re-ranking has occurred among the boroughs in respect of this index. The highest figures are recorded in Paddington, Kensington and St. Pancras, whereas in 1931 the worst conditions were found in Finsbury, Shoreditch and Bethnal Green. In general, the rank correlation between the indexes for the two years is fairly high.

The 1951 Census sought to obtain some wholly new information about housing conditions by asking questions about certain household arrangements. The results for London are presented in tables showing (separately) the percentage of households having exclusive use, sharing or being entirely without piped water, cooking stove, kitchen sink, water eloset and fixed bath. It is not certain that the results of the new inquiry have come up to the expectations of the designers of the census form either on statistical grounds or as sources of unambiguous information about social conditions in different areas : statistically, the value of the results has apparently been somewhat impaired by misunderstanding of the questions on the part of householders; and sociologically, it appears that the results need to be interpreted in the light of other information about household structure. It is, in fact, not nearly as easy as might have been supposed to decide whether relatively extensive sharing of facilities, or even their absence, is an unambiguous sign of poor social conditions in any given area. Some form of factor analysis might be useful in determining significent criteria from this new material. The new tables showing the distribution of heads of households by age, sex and marital condition might prove specially useful in that connexion.

The report contains trbles of the percentage of the male population aged seventeen to nineteen in the various boroughs who were engaged in full-time education. They range from 30 per cent in Hampstead to 1 per cent in Shoreditch, and the figures are highly correlated with the percentege of occupied males in the boroughs who stated their "terminal education age" as being seventeen years or more. The boroughs with high "secondary education" percentages tend also to be those with high proportions of professional workers and those with relatively high proportions of residents from outside London.

\section{FLAX IN NEW ZEALAND}

$\mathrm{N}^{\mathrm{m}}$ WW ZEALAND has a native plant, Phormium tenax, the leaves of which yield a useful cordage fibre, long known in New Zealand as 'flax' and in commerce as 'New Zealand flax'. This fibre is very different from true flax, the bast fibres from Linum usitatissimum. The confusion of terms was immaterial before 1940, but in that year New Zealand began to grow crops of the true flax, designating it 'linen flax' to differentiate it from the native fibre. Outside New Zealand it is now customary to refer to the native fibre as 'Phormium' fibre or 'New Zealand hemp''hemp' being used as a general term to include all the cordage fibres, while the original hemp fibre from Cannabinus sativa is described as 'true hemp'.

In Great Britain, as a consequence of the cutting off in 1940 of flax supplies from the Continent of
Europe, the Ministry of Supply appesled to New Zealand to grow fifteen thousand acres of flax to help fill the gap. The response was prompt, favourable and energetic. Fortunately, three years before the War the New Zealand Department of Scientific and Industrial Research had arranged for the officers of its Agronomy Division to make investigations of flax growing and processing in association with the Fields Division of the New Zealand Department of Agriculture; and when the crisis came, the officers were able to advise with confidence where and how the flax could be grown, and what yields of fibre and seed might be expected. But no organization was in being ; in so novel a situation the difficulties were immense, for the farmers had no knowledge of the flax crop and the engineering firms had no experience of making the processing mochinery. The problem was threefold-to establish an industry, to grow the crop and to process it; and the problem was successfully solved, the success being due to splendid team-work.

A report of how all this was done has been prepared by Mr. J. W. Hadfield, formerly director of the Agronomy Division, N.Z. Department of Scientific and Industrial Research*. To start with, a Linen Flax Management Committee was set up, to which Mr. Hadfield was seconded as director of linen flax production. It was arranged that the Department of Agriculture should organize and control all field operations, the arranging of contracts, sowing and harvesting; that the Marketing Department should handle the export of fibre, tow and seed; and that a Linen Flax Section should be established under the Department of Industries and Commerce to erect mills and carry out all factory operations. The co-operation was secured of the Public Works Department, which undertook the purchase of sites, letting tenders, and supervising the construction of factory buildings and retting tanks. The machinery problem was solved by the help of the Railways Department workshops, which supplied locomotive boilers to the mills and manufactured flax-processing machinery based on European models.

In a few months the new industry was established. The speed with which this co-operative enterprise was developed is revealed by the captions of two photographs in the report: "Instructions to grow flax were received in June 1940. Sowing commenced four months later, and harvesting in January 1941. . . Flax mills were being built while the crops they were to process were growing. The first fibre was delivered from the mills in March 1941".

Part 1 of the report is a plain record of plans and achievements and describes the fascinating details of how the industry was established, without omitting mention of the inevitable disappointments and criticisms. Part 2 describes the application of the general principles of flax growing to the particular conditions of the seventeen areas in the South Island in which the flax was grown. Part 3 describes the processing methods followed at the mills set up in the various growing areas.

It was inevitable that the hasty but successful improvization of flax production in 1940 should be carried out without immediate regard to cost ; more than thirteen thousand acres were actually sown with flax in 1940, and even greater acreages in succeeding years. But after the War, when it became necessary

- Linen Flax Fibre Production in New Zealand. By J. W. Hadfeld. Pp. xviii + 125. (New Zealand : The Linen Flax Corporation of N.Z., and the N.Z. Departments of Agriculture, Industries and Commerce, and Scientiflc and Industrial Research, 1953.) n.p. 